\title{
Calcium-Dependent Inactivation of Calcium Current in Synaptic Terminals of Retinal Bipolar Neurons
}

\author{
Henrique von Gersdorff and Gary Matthews \\ Department of Neurobiology and Behavior, State University of New York, Stony Brook, New York 11794-5230
}

Giant synaptic terminals ( $\sim 10 \mu \mathrm{m}$ diameter) of bipolar neurons from goldfish retina were used to directly investigate calciumdependent inactivation of presynaptic calcium current. During sustained depolarization, calcium current was initially constant for a period lasting up to several hundred milliseconds and then it declined exponentially. The duration of the initial delay was shorter and the rate of inactivation was faster with larger calcium current. The fastest time constant of inactivation (in the range of $2-5 \mathrm{sec}$ ) was observed under weak calcium buffering conditions. Inactivation was attenuated when external $\mathrm{Ca}^{2+}$ was replaced with $\mathrm{Ba}^{2+}$ and when terminals were dialyzed with high concentrations of internal BAPTA. Elevation of intracellular calcium concentration $\left(\left[\mathrm{Ca}^{2+}\right]_{\mathrm{i}}\right.$ ) by application of the calcium ionophore ionomycin or by dialysis with pipette solutions containing buffered elevated $\left[\mathrm{Ca}^{2+}\right]$ produced inactivation of calcium current. The rate of recovery from inactivation was not determined by the recovery of $\left[\mathrm{Ca}^{2+}\right]$, to baseline after a stimulus. The results demonstrate that presynaptic calcium current in bipolar neurons is inactivated by elevated $\left[\mathrm{Ca}^{2+}\right]_{\text {, }}$, but the inactivation is $\sim 100$-fold slower than previously described calcium-dependent inactivation in other types of cells.

Key words: calcium; inactivation; negative feedback; presynaptic mechanisms; calcium channe/s; retina
Calcium-dependent inactivation of calcium current was first described in Paramecium by Brehm and Eckert (1978) and in molluscan neurons by Kostyuk and Krishtal (1977) and Tillotson (1979). It has subsequently been shown to underlie calciumchannel inactivation in various neuronal and non-neuronal cell types. Studies of calcium-dependent inactivation of neuronal calcium channels have been limited for the most part to somatic calcium currents because direct electrophysiological measurements from synaptic terminals are generally not feasible. Among the exceptions is the giant synaptic terminal of ON-type bipolar neurons from the retina of goldfish (Kaneko and Tachibana, 1985; Heidelberger and Matthews, 1992), which have proven useful for the study of presynaptic calcium current and its regulation by neurotransmitters (Heidelberger and Matthews, 1991, 1994; Matthews et al., 1994). These retinal interneurons do not produce sodium-dependent action potentials and are thought to be depolarized tonically during illumination (Saito et al., 1979, 1983). Their physiological response therefore involves sustained activation of presynaptic calcium channels, a situation that is likely to promote calcium-dependent inactivation of calcium current. Therefore, we have examined inactivation of calcium current and its calcium dependence in synaptic terminals of retinal bipolar neurons. Calcium-dependent inactivation was indeed observed during prolonged depolarization, but the time course of inactivation was substantially slower (on a time scale of seconds) than calcium-dependent inactivation in other types of cells. Thus, calcium-dependent inactivation of calcium channels provides feedback inhibition of synaptic release in bipolar-cell terminals,

\footnotetext{
Received July 31, 1995; revised Sept. 14, 1995; accepted Sept. 21, 1995.

This work was supported by NIII Grant EY03821 and by NRSA Fellowship EY06506.

Correspondence should be addressed to Dr. Gary G. Matthews at the above address.

Copyright $(1995$ Society for Neuroscience $\quad 0270-6474 / 95 / 160115-08 \$ 05.00 / 0$
}

but on a slow time scale that does not limit transmitter release during the first several hundred milliseconds of illumination.

\section{MATERIALS AND METHODS}

Bipolar neurons were acutely isolated from goldfish retina after papain digestion as described (Tachibana, 1983; Heidelberger and Matthews, $1992)$, and recordings were made at room temperature $\left(20-24^{\circ} \mathrm{C}\right)$ within 4-6 $\mathrm{hr}$ of dissociation. Isolated cells retained the distinctive morphology of type Mb1 bipolar neurons (Ishida et al., 1980; Yazulla et al., 1987) especially the large bulbous synaptic terminal $(10-12 \mu \mathrm{m}$ in diameter) Whole-cell patch-clamp recordings were made from intact cells (i.e., with dendrites, cell body, connecting axon, and synaptic terminal) or from isolated terminals, which were obtained by severing the axon of intact cells, or from visual identification of spontaneously isolated terminals (Matthews et al., 1994; von Gersdorff and Matthews, 1994a). In intact cells, the calcium current originates predominantly from the synaptic terminal (Heidelberger and Matthews, 1992; Tachibana et al., 1993) Results from intact cells (patch pipette on cell body or synaptic terminal) and from isolated terminals were indistinguishable and are combined here.

The external solution contained (in $\mathrm{mM}$ ): $\mathrm{NaCl} 120, \mathrm{KCl} 2.6, \mathrm{MgCl}_{2} 1.0$, $\mathrm{CaCl}_{2} 2.5$, glucose 10, HEPES 10, $\mathrm{pH} 7.3$ with $\mathrm{NaOH}$. Patch pipettes were filled with a solution containing (in $\mathrm{mM}$ ): Cs-gluconate 120, TEA-Cl 10, $\mathrm{MgCl}_{2} 2.0, \mathrm{Na}_{2}$ ATP 2.0, GTP 0.5, HEPES 10 or $25, \mathrm{pH} 7.2$, with CsOH. In some experiments, additional $\mathrm{MgCl}_{2}$ was added to bring the total concentration to $3 \mathrm{mM}$. Calcium buffering was varied according to experimental goals by adding BAPTA (Cs salt), EGTA (neutralized with $\mathrm{CsOH}$ ), or mixtures of EGTA and calcium-saturated EGTA (prepared as described in Neher, 1988) or NTA. For measurements of internal $\left[\mathrm{Ca}^{2+}\right]$, the pipette solution also contained 0.1 or $0.2 \mathrm{~mm}$ Fura- 2 or furaptra. Ratiometric measurements of indicator fluorescence were made using a photomultiplier tube, as detailed in Heidelberger and Matthews (1992).

\section{RESULTS}

The synaptic terminals of bipolar neurons from the goldfish retina exhibit a single type of slowly inactivating calcium current that can be blocked by dihydropyridines and potentiated by Bay-K-8644 (Heidelberger and Matthews, 1992; Tachibana et al,, 1993). During depolarizations lasting up to several hundred milliseconds, there is little inactivation of calcium current. This behavior is 

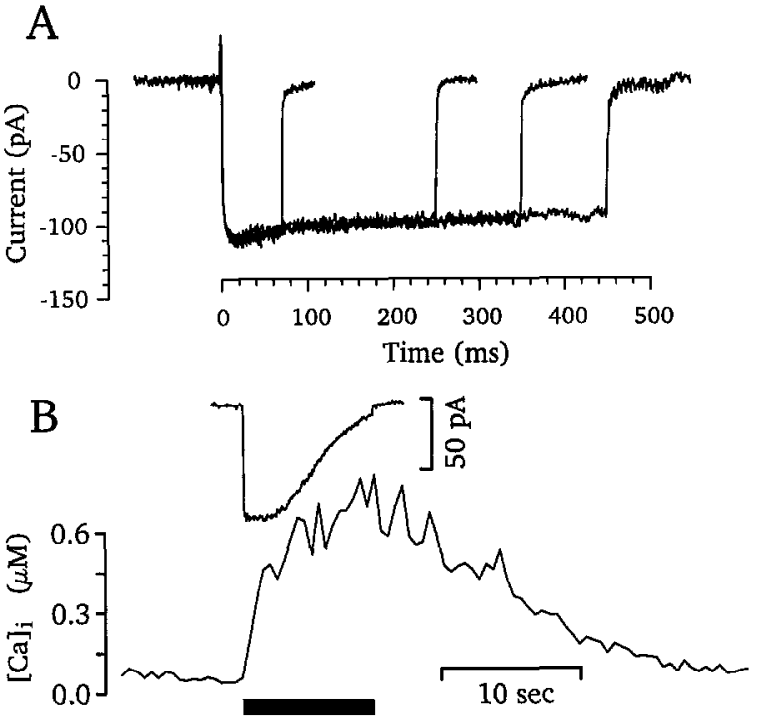

Figure 1. Inactivation of calcium current in bipolar neurons occurs only with long-duration depolarizations. $A$, Superimposed responses to depolarizations of increasing duration (70, 250, 350, and 450 msec), starting at time $=0$ on the time scale. Holding potential was $-60 \mathrm{mV}$, and the depolarization was to $-10 \mathrm{mV}$. Calcium buffering: $0.5 \mathrm{~mm}$ BAPTA. $B$, Current elicited by a $10 \mathrm{sec}$ depolarization from -60 to $-20 \mathrm{mV}$ (top), together with intraterminal $\left[\mathrm{Ca}^{2+}\right]_{\mathrm{i}}$ calculated from fluorescence of Fura-2 (bottom). The timing of depolarization is indicated by the dark bar. Calcium buffering: 5 mm EGTA, $0.1 \mathrm{~mm}$ Fura-2.

illustrated in Figure $1 A$, which shows superimposed responses to depolarizations of increasing duration, ranging from 70 to 450 msec. At these durations, there was little sag in the current that would indicate calcium-channel inactivation. This behavior is quite different from that of L-type channels in cardiac cells and smooth muscle cells in which calcium-dependent inactivation begins without delay after depolarization and proceeds along an exponential time course with a time constant in the range of 50-100 msec (Yue et al., 1990; Giannattasio et al., 1991; Neely et al., 1994). In neurohypophysial nerve endings, calcium current also inactivates on this more rapid time scale (Lemos and Nowycky, 1989). Calcium currents in these cells would inactivate almost completely on a time scale in which calcium current in bipolar-cell terminals inactivates hardly at all (Fig. 1A). The absence of rapid inactivation persisted in bipolar-cell terminals when an excess of $\mathrm{Mg}^{2+}$ was added to the internal solution to enhance activity of $\mathrm{Mg}^{2+}$-dependent enzymes. With $2 \mathrm{~mm}$ $\mathrm{Na}_{2}$ ATP $+3 \mathrm{mM} \mathrm{MgCl}_{2}, \mathrm{Ca}^{2+}$ current at the end of a $250 \mathrm{msec}$ pulse was $91 \pm 2 \%$ of the initial current (mean $\pm \mathrm{SEM} ; n=24$ ). In addition, inactivation speed was affected very little when the calcium-buffering capacity of the internal solution was reduced. With 0.1-0.5 mM EGTA in the recording pipette, calcium current at the end of a $250 \mathrm{msec}$ depolarization was $89 \pm 2 \%$ of the initial current (mean $\pm \mathrm{SEM} ; n=12$ ), which is not substantially different from the comparable value of $93 \pm 1 \%$ with high buffer capacity ( $10 \mathrm{~mm}$ EGTA; $n=12)$. Thus, the absence of rapid inactivation does not seem to be attributable to the recording conditions.

Although the presynaptic calcium current of bipolar neurons shows little inactivation on a fast time scale, more prolonged depolarizations lasting several seconds do produce a slow decline in calcium current (Fig. $1 B$ ), which is associated with a sustained increase in intraterminal $\left[\mathrm{Ca}^{2+}\right]$ during the depolarization. We
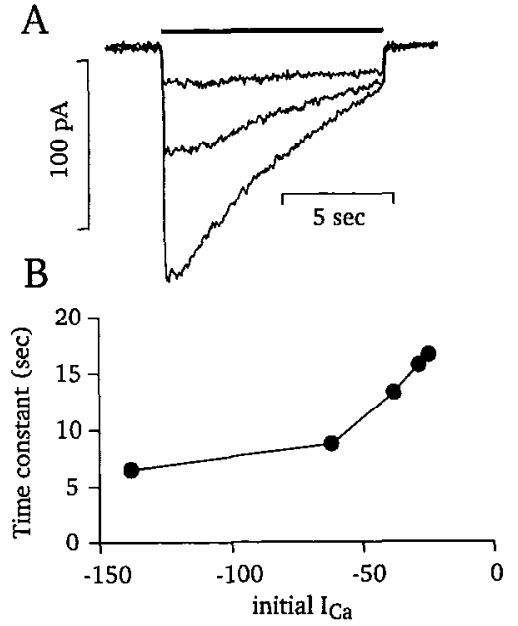

Figure 2. Inactivation depends on initial magnitude of calcium current. $A$, Superimposed responses to $10 \mathrm{sec}$ depolarizing pulses from -60 to -20 $\mathrm{mV}$. A series of pulses was given with a $15 \mathrm{sec}$ interpulse interval, which is insufficient for complete recovery from inactivation between pulses (see Fig. 9). Thus, the initial amount of current after onset of the depolarization declined progressively during the series. After the initial plateau phase of current, the current declined with an approximately exponential time course. $B$, The exponential time constant of the decaying phase of the current is plotted against the initial magnitude of the current for the cell of $A$.

will demonstrate here that this slow and delayed inactivation of $\mathrm{Ca}^{2+}$ current in bipolar-cell terminals has the propertics expected for calcium-dependent inactivation, even though it occurs on a time scale 100-fold slower than the more rapid inactivation of calcium channels commonly produced by calcium influx.

\section{Inactivation depends on the magnitude of the calcium current}

One hallmark of calcium-dependent inactivation is that the speed and degree of inactivation depend on the amplitude of the calcium current (Brehm and Eckert, 1978; Tillotson, 1979). Figure 2 shows that this is true for the slow inactivation of calcium current in bipolar-cell synaptic terminals. A series of $10 \mathrm{sec}$ depolarizations was applied at a rate that allowed insufficient time for complete recovery from inactivation (Fig. 9) between successive pulses. With larger currents, the duration of the initial flat period before onset of inactivation was shorter, and the rate and degree of inactivation were larger. To characterize the rate of inactivation, an exponential decay was fitted to the declining portion of the current. The slowing of the time constant of inactivation with smaller initial currents is summarized in Figure $2 B$ for the cell of Figure $2 A$. Even with large initial currents, the time constant did not typically exceed $4-5 \mathrm{sec}$, averaging $4.6 \pm 1.0 \mathrm{sec}$ in 10 cells (for initial currents of $100 \mathrm{pA}$ or greater).

\section{Calcium buffers reduce inactivation}

Calcium-dependent inactivation can also be reduced by the addition of exogenous intracellular calcium buffers (Brehm and Eckert, 1978; Bechem and Pott, 1985; Kalman et al., 1988; Köhr and Mody, 1991; Imredy and Yue, 1992). We examined this by including various concentrations of BAPTA in the pipette solution during whole-cell recordings from bipolar neurons. Figure 3 shows examples of the inactivation of calcium current in threc different bipolar neurons with $0.5,5$, or $10 \mathrm{~mm}$ BAPTA. To test for inactivation, a series of $250 \mathrm{msec}$ depolarizations from -60 to $-10 \mathrm{mV}$ was given at 1 pulse/sec. The superimposed traces in 

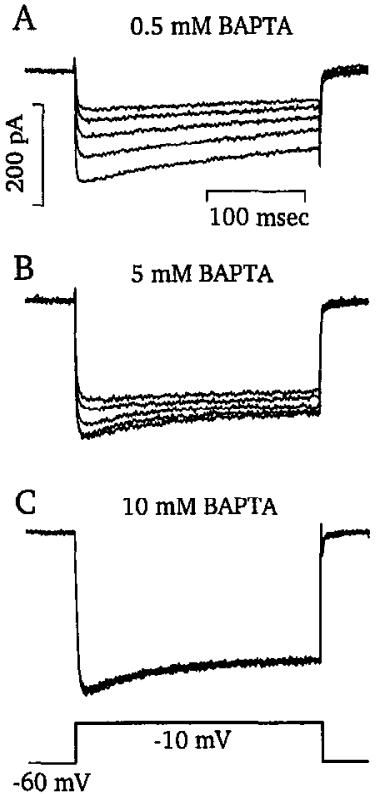

Figure 3. Inactivation of calcium current is retarded by intratcrminal BAPTA. The traces show superimposed calcium currents elicited by five successive depolarizations given at $1 \mathrm{pulse} / \mathrm{sec}$. The timing and duration of the depolarization is indicated in the bottom trace. The calibration bars in $A$ also apply to $B$ and $C$. BAPTA (Cs salt) was added to the pipette solutions at $0.5 \mathrm{~mm}(A), 5 \mathrm{~mm}(B)$, or $10 \mathrm{~mm}(C)$.

Figure $3 A$ show calcium currents elicited by five successive depolarizations in a cell with light calcium buffering ( $0.5 \mathrm{mM}$ BAPTA), which allowed rapid accumulation of inactivation. With $5 \mathrm{~mm}$ BAPTA (Fig. $3 B$ ), inactivation was much less pronounced within the train of five pulses, and with $10 \mathrm{~mm}$ BAPTA (Fig. $3 \mathrm{C}$ ) there was no inactivation. Thus, BAPTA reduced inactivation. The results from a large number of such experiments are summarized in Figure 4. The graphs show the calcium current measured at either $2 \mathrm{sec}$ (open circles) or $5 \mathrm{sec}$ (filled circles) after onset of a train of depolarizing pulses, given at 1 pulse/sec as in Figure 3, plotted against the magnitude of the initial calcium current at the beginning of the train. The diagonal straight line in each case shows the expected relation if there were no inactivation (i.e., test calcium current equal to initial calcium current), and inactivation is indicated by the points falling above the line. Each data point shows the results for a different synaptic terminal. With $0.5 \mathrm{~mm}$ BAPTA in the pipette solution (Fig. $4 A$ ), there was substantial inactivation measured at both 2 and $5 \mathrm{sec}$ after onset of the pulse train (i.e., current elicited by the third and sixth pulses in the train). The amount of inactivation was greater at larger initial currents, which indicates again the current-dependence of inactivation, as shown previously in Figure 2 . At $5 \mathrm{~mm}$, BAPTA virtually eliminated inactivation measured $2 \mathrm{sec}$ after depolarization, even with large initial currents. After 5 sec depolarization, some inactivation was observed, but only if the initial current was greater than $\sim 200 \mathrm{p} \Lambda$ (Fig. $4 B$ ). With $10 \mathrm{~mm}$ BAPTA, there was little inactivation, regardless of the size of the initial current. These effects of calcium buffers are also consistent with the idea that inactivation of the presynaptic calcium current is calcium-dependent.

\section{Inactivation is reduced by external barium}

Previous work has shown that calcium-dependent inactivation is less pronounced when barium ions replace calcium as the charge
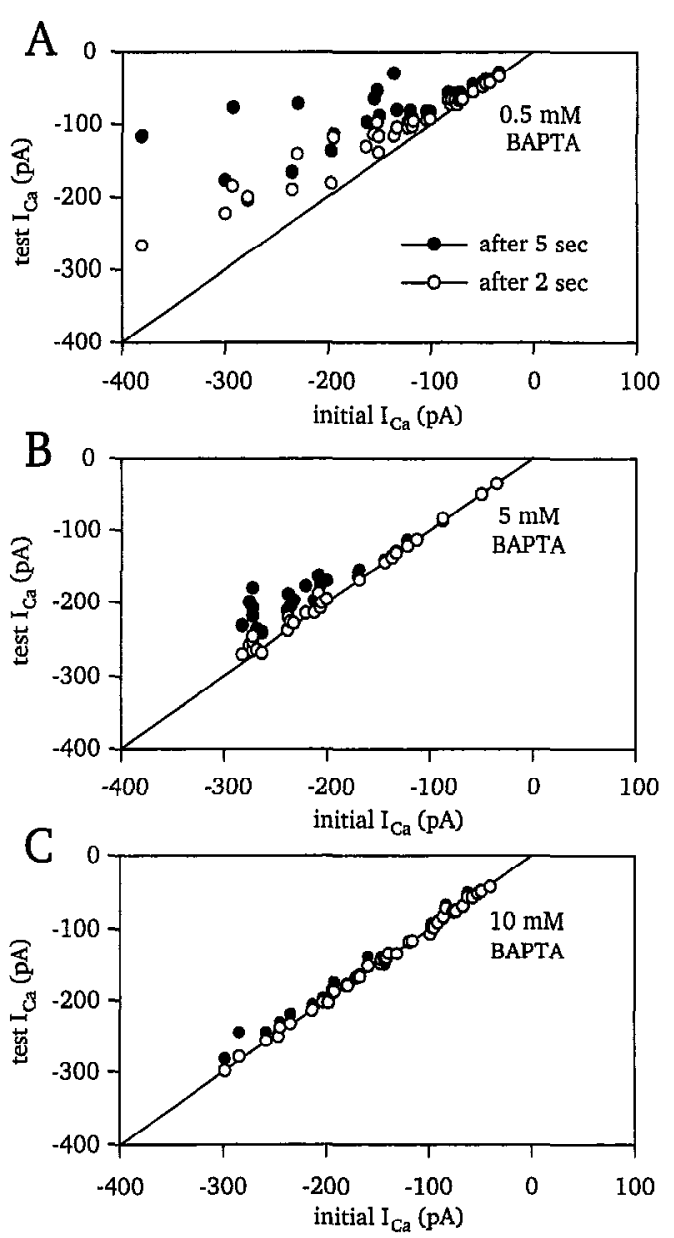

Figure 4. Inactivation depends on the size of the initial current and on calcium buffering. BAPTA was added to the pipette solution at $0.5 \mathrm{~mm}$ $(A), 5 \mathrm{~mm}(B)$, or $10 \mathrm{mM}(C)$. A series of $250 \mathrm{msec}$ depolarizations was given at 1 pulse/sec. The initial $I_{\mathrm{Ca}}$ was in response to the first depolarizing pulse in the train. The test calcium current (test $I_{C a}$ ) was the maximum current in response to the third pulse in the train (i.e., $2 \mathrm{sec}$ after the onset of the pulsc scrics; $O$ ) and in response to the sixth pulse ( $5 \mathrm{sec} ; 0)$. Each pair of filled and open circles at a particular value of initial $I_{\mathrm{Ca}}$ represents results for a single terminal. The diagonal line shows the expected behavior in the absence of inactivation, with test $I_{\mathrm{Ca}}=$ initial $I_{\mathrm{Ca}}$. The number of terminals studied at each buffering level was 35 (0.5 mM BAPTA), 27 (5 mM BAPTA), and 39 (10 mM BAPTA).

carrier through calcium channels (Brehm and Eckert, 1978; Tillotson, 1979; Chad and Eckert, 1986; Yue et al., 1990). Therefore, we examined the effect of external $\mathrm{Ba}^{2+}$ on the inactivation of bipolar-cell calcium channels. Figure $5 A$ shows results of an experiment in which brief depolarizing pulses were given to assess the amount of calcium current (filled circles) before and after 20 sec depolarizations were given to elicit inactivation. With $2.5 \mathrm{~mm}$ $\mathrm{Ba}^{2+}$ in the external solution, the prolonged depolarization produced a modest decline in the test current, which recovered with time after the depolarization. When the external $\mathrm{Ba}^{2+}$ was replaced with $2.5 \mathrm{mM} \mathrm{Ca}^{2+}$ (shaded region), prolonged depolarization produced almost complete inactivation of the calcium current. Note that the inactivation was more complete in $\mathrm{Ca}^{2+}$ even though the current amplitude was greater in $\mathrm{Ba}^{2+}$. The results from nine similar experiments are summarized in Figure $5 B$, which shows that the degree of inactivation produced by a $20 \mathrm{sec}$ depolarization was significantly less in $\mathrm{Ba}^{2+}$-containing external 

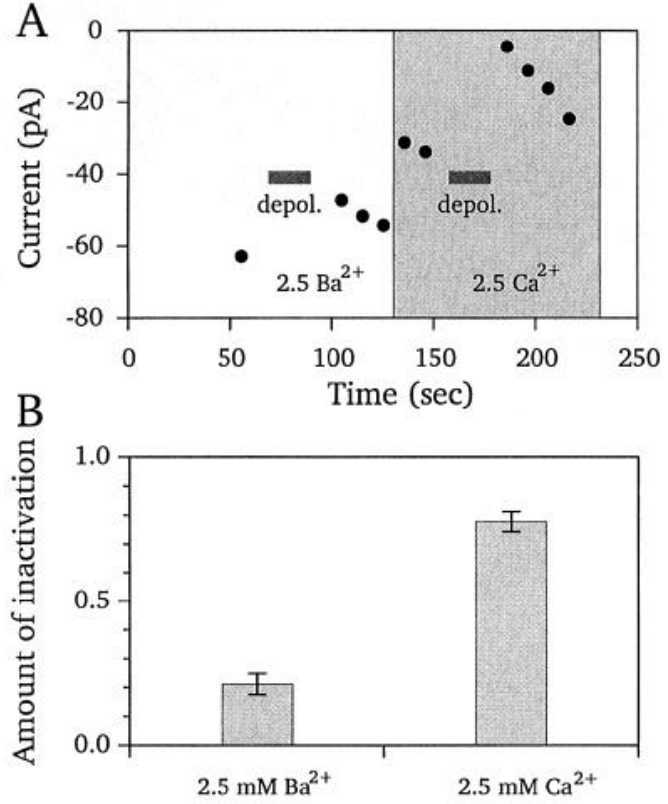

Figure 5. External $\mathrm{Ba}^{2+}$ reduces inactivation. $A$, Calcium current amplitude ( ) before and after $20 \mathrm{sec}$ inactivating stimuli (dark bars) with 2.5 $\mathrm{mm}$ external $\mathrm{Ba}^{2+}$ or $2.5 \mathrm{~mm}$ external $\mathrm{Ca}^{2+}$. $B$, Average amount of inactivation in $\mathrm{Ba}^{2+}$ and $\mathrm{Ca}^{2+}$ external solutions from nine cells. Amount of inactivation is defined as $1-I_{\text {after }} / I_{\text {before }}$, where $I$ is the calcium current in response to a brief test depolarization before or after an inactivating depolarizing stimulus. Vertical lines indicate \pm 1 SEM.

solution than in $\mathrm{Ca}^{2+}$-containing solution. Thus $\mathrm{Ba}^{2+}$ reduced inactivation, as expected for calcium-dependent inactivation.

\section{Inactivation is reduced at positive membrane potentials}

Another hallmark of calcium-dependent inactivation is a U-shaped voltage-dependence of inactivation (Brehm and Eckert, 1978; Tillotson, 1979). This arises because the inactivation depends on calcium influx rather than on membrane voltage per se. The amount of calcium influx produced by a depolarization first increases with increasing depolarization, as calcium channels open in response to the stimulus. Then, with further depolarization, calcium influx declines because of reduced driving force for calcium entry, even if all calcium channels are open. In bipolarcell synaptic terminals, measurements with intraterminal Fura-2 show that the elevation of intracellular calcium concentration $\left(\left[\mathrm{Ca}^{2+}\right]_{\mathrm{i}}\right)$ achieved by depolarization increases sharply from -40 to $-10 \mathrm{mV}$ and then declines with further depolarization to potentials more positive than $+20 \mathrm{mV}$ (von Gersdorff and Matthews, 1994a). The voltage-dependence of inactivation of the presynaptic calcium current in bipolar cells has a similar shape, as shown in Figure 6. The state of the calcium current was sampled by using voltage ramps (Heidelberger and Matthews, 1992) given just before and $5 \mathrm{sec}$ after termination of a $20 \mathrm{sec}$ depolarizing step to various membrane voltages. In the example shown in Figure $6 A$, the calcium current was strongly inactivated by a depolarizing step to $-20 \mathrm{mV}$, but inactivation was reduced at +40 $\mathrm{mV}$ and virtually absent at $+80 \mathrm{mV}$. The results from a number of such experiments are shown in Figure 6B. As expected for calciumdependent inactivation, the amount of inactivation was greatest after depolarizing steps near the peak of the calcium current and then declined with depolarization to more positive values.
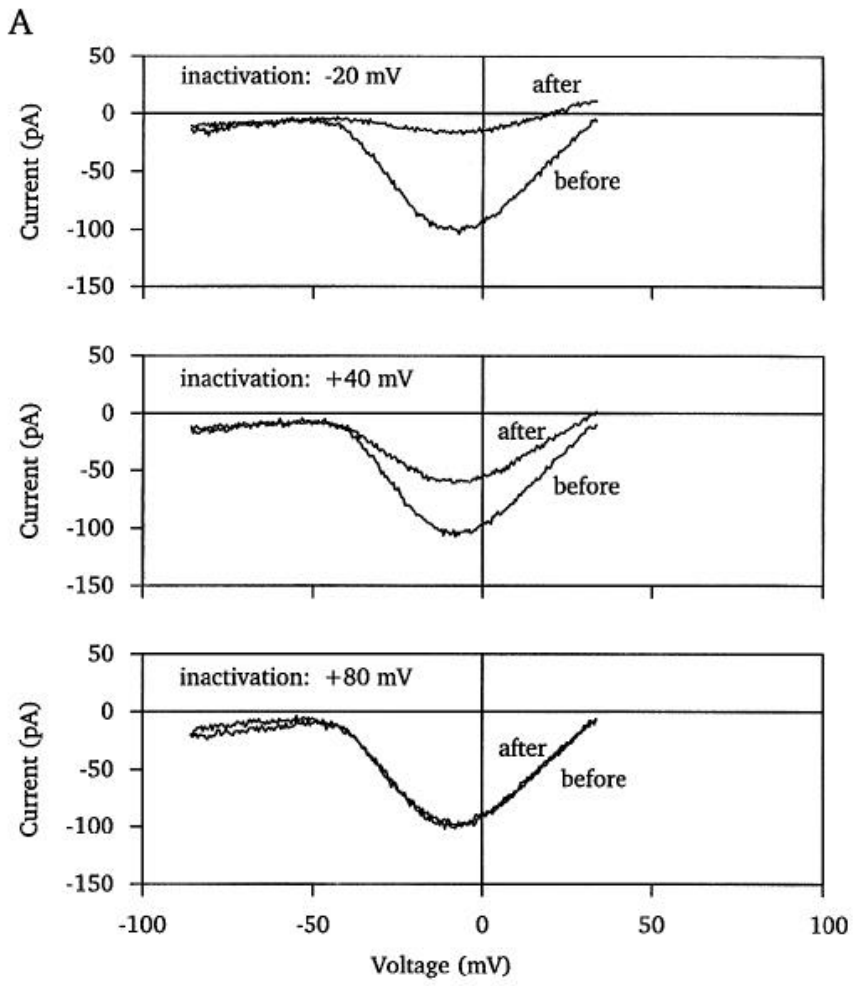

B

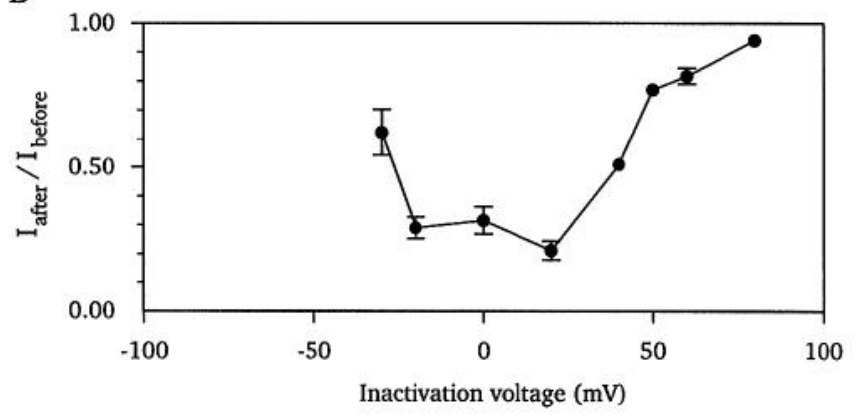

Figure 6. Voltage-dependence of inactivation of calcium current. A, Responses to voltage ramps before and after $20 \mathrm{sec}$ inactivating depolarizations to the indicated voltages. Ramp speed was $100 \mathrm{mV} / \mathrm{sec}$. $B$, Normalized peak calcium current after an inactivating stimulus plotted against the voltage of the inactivating stimulus. Current after the stimulus was divided in each case by the peak calcium current measured just before the inactivating stimulus. Vertical bars show \pm SEM, and data points are averages of $6,13,4,8,1,2,11$, or 2 experiments (in order from negative to positive).

\section{Calcium current is inactivated by elevated $\left[\mathrm{Ca}^{2+}\right]_{i}$ induced by ionomycin}

The results described so far demonstrate that the inactivation of calcium current has properties expected of calcium-dependent inactivation under conditions in which the inactivation is produced by calcium influx through the calcium channels themselves. To determine whether the calcium current could also be inactivated when $\left[\mathrm{Ca}^{2+}\right]_{\mathrm{i}}$ was elevated by other means, we elevated intraterminal calcium by external superfusion with the calcium ionophore ionomycin. An example is shown in Figure 7. Calcium current was sampled with periodic $70 \mathrm{msec}$ depolarizations (responses to two of which are shown in the upper traces), and ionomycin was applied at the indicated time in the lower trace. We found that ionomycin at high concentration elevated $\left[\mathrm{Ca}^{2+}\right]_{\mathrm{i}}$ to levels that saturated the high-affinity calcium indicator Fura-2, 


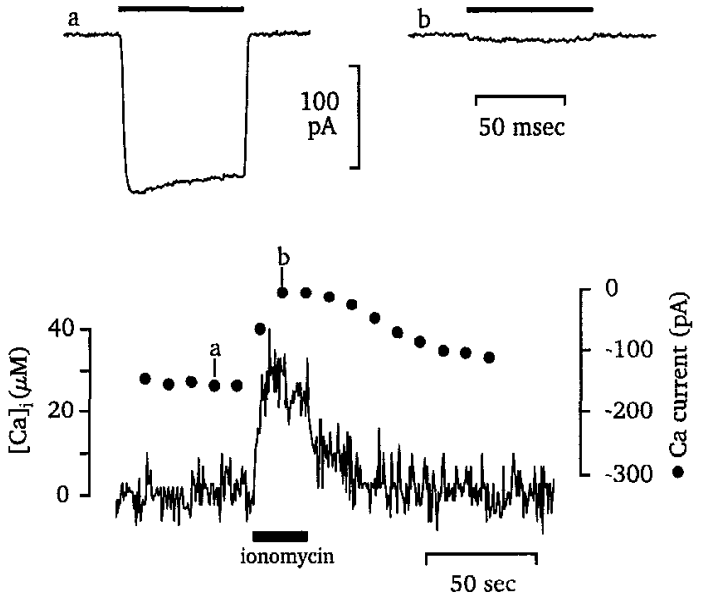

Figure 7. Ionomycin elevates intraterminal $\left[\mathrm{Ca}^{2+}\right]_{i}$ and induces inactivation of calcium current. Upper traces show examples of calcium current measured before application of $10 \mu \mathrm{g} / \mathrm{ml}$ ionomycin (at $a$ in bottom traces) and during application (at $b$ ). The filled circles show the amplitude of inward calcium current (right axis), and the noisy trace shows $[\mathrm{Ca}]_{\mathrm{i}}$ calculated from fluorescence of furaptra (left axis).

so the increase in $\left[\mathrm{Ca}^{2+}\right]_{i}$ was monitored instead with the lowaffinity calcium indicator furaptra (Konishi et al., 1991). During application of ionomycin, $\left[\mathrm{Ca}^{2+}\right]_{\mathrm{i}}$ increased to between 20 and 30 $\mu \mathrm{M}$, and the calcium current almost disappeared. After ionomycin was removed, $\left[\mathrm{Ca}^{2+}\right]_{\mathrm{i}}$ returned to rest and the calcium current recovered. This demonstrates that exogenously added calcium is able to inactivate presynaptic calcium current in bipolar neurons. Also, because the terminal was held at $-60 \mathrm{mV}$ at all times except for the brief test depolarizations, the inactivation did not require depolarization. Indeed, even closed channels are inactivated, provided $\left[\mathrm{Ca}^{2+}\right]_{i}$ increases to a sufficiently high level. Similar effects of ionomycin were observed in a total of 11 synaptic terminals, with the calcium current in the presence of ionomycin averaging $9.9 \pm 2.9 \%$ of the control current (mean \pm SEM).

\section{Dialysis with elevated calcium}

Another way to elevate intraterminal $\left[\mathrm{Ca}^{2+}\right]_{i}$ without activation of calcium current is by dialysis with whole-terminal pipette solutions containing buffered, elevated $\left[\mathrm{Ca}^{2+}\right]$. When terminals were dialyzed in this manner with solutions containing a calculated free $\left[\mathrm{Ca}^{2+}\right]$ of $1.4 \mu \mathrm{M}$ (Fig. 8A), the calcium current was unaffected. Similar results were observed in a total of five terminals. Simultaneous Fura-2 measurements indicated that free $\left[\mathrm{Ca}^{2+}\right]$ achieved within the terminals was $\sim 1 \mu \mathrm{M}$, whereas the free $\left[\mathrm{Ca}^{2+}\right]$ in the pipette solution was estimated at $2 \mu \mathrm{m}$ with a calcium-selective electrode. The difference between the levels in the cell and in bulk solution likely represents the effects of endogenous cellular calcium buffering. In contrast, when the $\left[\mathrm{Ca}^{2+}\right]_{\text {free }}$ of the pipette solution was increased to $52 \mu \mathrm{M}$ (Fig. $8 B$ ), the calcium current declined to zero along an approximately exponential time course with a time constant of $28 \mathrm{sec}$ in Figure $8 B$. Similar results were also obtained with $20 \mu \mathrm{M}\left[\mathrm{Ca}^{2+}\right]_{\text {free }}$. When results from experiments with 20 or $52 \mu \mathrm{M}\left[\mathrm{Ca}^{2+}\right]_{\text {free }}$ were combined, the average time constant of inactivation was $35 \pm 8 \mathrm{sec}$ (mean $\pm \mathrm{SEM}, n=$ 6). This confirms in a different manner that, as with ionomycin, exogenously supplied calcium produces inactivation, and that closed channels inactivate in the presence of elevated $\left[\mathrm{Ca}^{2+}\right]_{i}$. Inactivation did not occur during dialysis with a level of $\left[\mathrm{Ca}^{2+}\right]$ (i.e., $1.4 \mu \mathrm{M}$ ) that was similar to that achieved throughout the
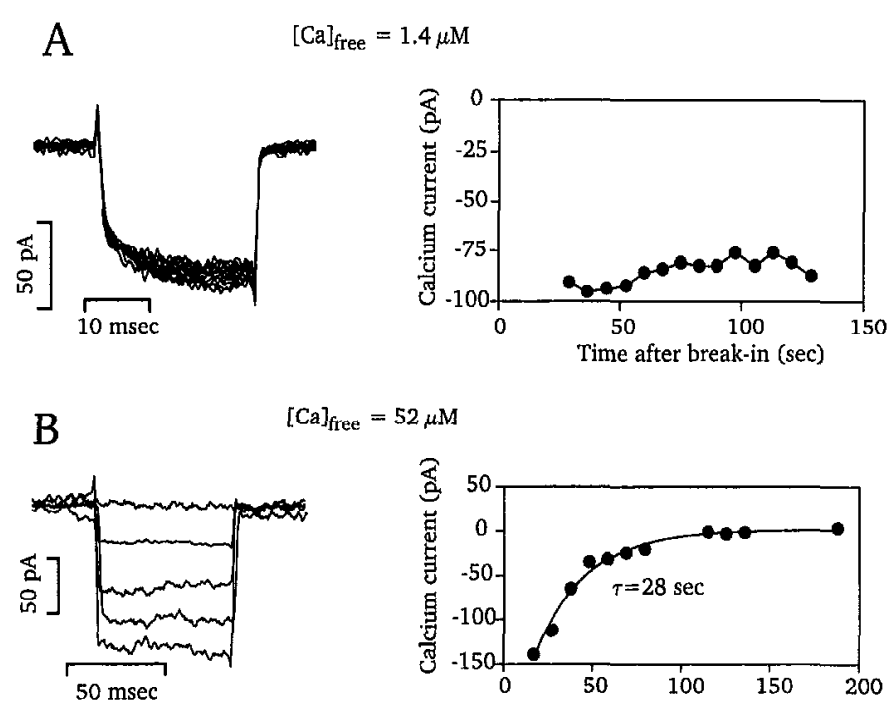

$[\mathrm{Ca}]_{\text {free }}=52 \mu \mathrm{M}$

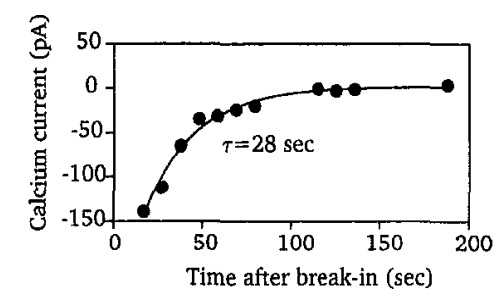

Figure 8. Internal dialysis with elevated $\left[\mathrm{Ca}^{2+}\right]$ inactivates calcium current. $A$, Dialysis with pipette solution containing calculated $\left[\mathrm{Ca}^{2+}\right]_{\text {frec }}$ of $1.4 \mu \mathrm{M}$. Superimposed responses to 14 test depolarizations from -60 to $-10 \mathrm{mV}$ (left). The graph (right) shows the calcium current versus time after break-in. The pipette solution contained (in mM): 9 CaEGTA, 1 $\mathrm{Cs}_{2}$ EGT $\Lambda$, and 0.1 Fura-2. Free $\left[\mathrm{Ca}^{2+}\right]$ measured with a calcium-selectivc electrode was $2 \mu \mathrm{M}$ in this solution. The calcium concentration reported in the terminal by Fura- 2 was $\sim 900 \mathrm{~nm}$ in this experiment, suggesting that cellular buffering influenced the achieved internal concentration. $B$, Dialysis with pipette solution containing calculated $\left[\mathrm{Ca}^{2+}\right]_{\text {free }}$ of $52 \mu \mathrm{M}$. Superimposed responses show calcium currents activated by test pulses from -60 to $-10 \mathrm{mV}$, whereas the graph shows current plotted against time after break-in. The smooth line is an exponential function fitted to the points by a least-squares criterion. The pipette solution contained (in $\mathrm{mM}$ ) $10 \mathrm{Cs}_{2} \mathrm{NTA}, 3 \mathrm{CaCl}_{2}$, and 0.1 furaptra. Measurements with a calciumselective electrode gave an estimated free $\left[\mathrm{Ca}^{2+}\right]$ of $68 \mu \mathrm{M}$ in this solution.

terminal as a whole during activation of calcium current (Fig. 1B). Instead, substantially higher levels of $\left[\mathrm{Ca}^{2+}\right]_{i}$ were required (Fig. $8 B$ ). This suggests that the relevant level of $\left[\mathrm{Ca}^{2+}\right]_{\text {; }}$ when inactivation is produced by depolarization is not the spatially averaged level achieved at a distance from the calcium channels, but rather corresponds to the much higher level near the membrane or near the open calcium channels themselves (Chad and Eckert, 1984; Fogelson and Zucker, 1985).

\section{Inactivation does not affect voltage dependence of calcium current}

We have shown that during inactivation the magnitude of the calcium current produced by step depolarizations is substantially reduced. To examine whether this reduction in the pulse responses is because of true inactivation of channels (i.e., removal from the openable pool) or is associated with a shift in the voltage-dependence of activation of the calcium channels, we compared the current-voltage relations of the calcium current before and after inactivation was induced with a prolonged depolarizing step. The current-voltage relation was assessed using voltage ramps at $100 \mathrm{mV} / \mathrm{sec}$, which provide a rapid indication of the voltage range over which calcium channels are activated (Heidelberger and Matthews, 1992). As shown in Figure 9, the shape of the ramp response was not substantially altered, suggesting that inactivation is produced by the closing of calcium channels, not by a shift in their voltage dependence. 


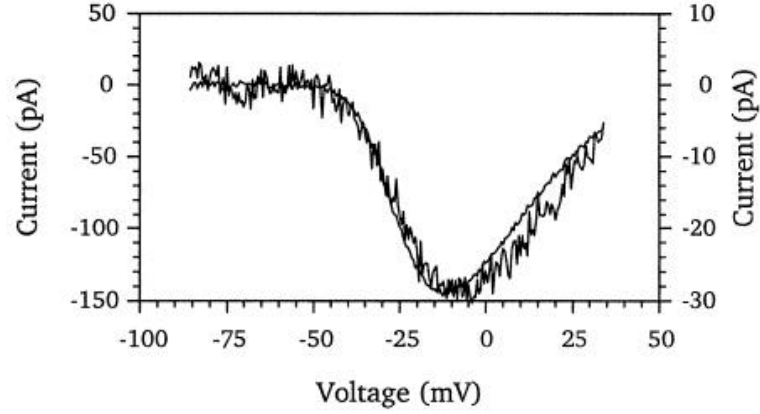

Figure 9. Ramp responses before and after inactivation are superimposable. Responses to voltage ramps at $100 \mathrm{mV} / \mathrm{sec}$ are shown before (smooth trace, left axis) and after (noisy trace, right axis) a $20 \mathrm{sec}$ depolarization from -60 to $-10 \mathrm{mV}$. In both traces, linear leak was subtracted by fitting a straight line to the current trace in the range from -80 to $-60 \mathrm{mV}$. Peak amplitudes are adjusted to be the same.

\section{Recovery from inactivation}

When $\left[\mathrm{Ca}^{2+}\right]_{\mathrm{i}}$ returned to rest after an inactivating stimulus, calcium current also recovered. We examined the rate of recovery by giving periodic brief depolarizing test pulses (which do not themselves cause accumulating inactivation) after a prolonged stimulus that produced inactivation. An example is shown in Figure $10 \mathrm{~A}$. The calcium current returned to the prestimulus control level along an exponential time course, with a time constant of $25 \mathrm{sec}$ in the example. By contrast, $\left[\mathrm{Ca}^{2+}\right]_{\mathrm{i}}$ returned to rest much more rapidly, with an exponential time constant of $8 \mathrm{sec}$ (Figure 10A). Thus, recovery from inactivation was not limited by the time course of return of $\left[\mathrm{Ca}^{2+}\right]_{i}$ to basal levels. The average time constant of recovery from inactivation is shown in Figure $10 B$ under various conditions of calcium buffering. The average in all cases was $\sim 25 \mathrm{sec}$, regardless of the amount of calcium buffer and
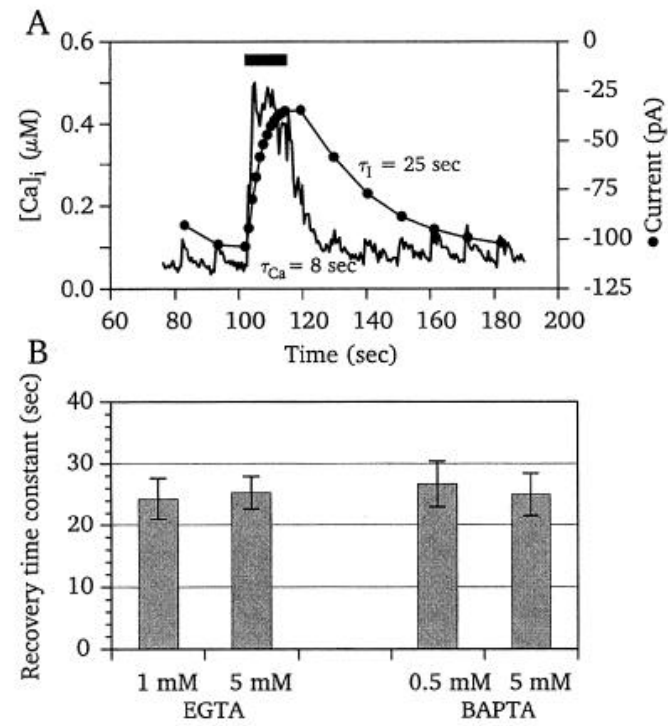

Figure 10. Recovery from inactivation. A, Calcium current (๑) was monitored with $70 \mathrm{msec}$ pulses given every $10 \mathrm{sec}$. During the period indicated by the dark bar, $250 \mathrm{msec}$ pulses were given at 1 pulse/sec to produce inactivation. $\left[\mathrm{Ca}^{2+}\right]_{\mathrm{i}}$ was monitored by including $0.1 \mathrm{~mm}$ Fura- 2 in the pipette solution. $B$, Average time constant for recovery of calcium current after inactivation. The bars show the average from $12(1 \mathrm{~mm}$ EGTA), 10 (5 mm EGTA), 17 (0.5 mм BAPTA), or 17 (5 mм BAPTA) experiments, and the vertical lines show \pm 1 SEM. regardless of whether the buffer was EGTA or BAPTA. This is further indication that the recovery of the calcium channels from inactivation is independent of $\left[\mathrm{Ca}^{2+}\right]_{i}$ after termination of the inactivating stimulus, provided $\left[\mathrm{Ca}^{2+}\right]_{\mathrm{i}}$ returned to the prestimulus level of $\sim 100 \mathrm{~nm}$.

\section{DISCUSSION}

The experiments reported here demonstrate that slow inactivation of presynaptic calcium channels in retinal bipolar neurons is a calcium-dependent process. The evidence is that (1) the degree and the rate of inactivation depended on the amount of calcium current; (2) inactivation was reduced when $\mathrm{Ba}^{2+}$ was the current carrier; and (3) exogenous $\mathrm{Ca}^{2+}$ inactivated the calcium channels, whereas BAPTA reduced inactivation. The calcium channels in goldfish bipolar neurons are L-type (Heidelberger and Matthews, 1992; Tachibana et al., 1993), but the calcium-dependent inactivation described here differs in a number of ways from calciumdependent inactivation in L-type channels from other types of cells. One striking difference is the speed of inactivation. In our experiments, inactivation did not begin until several hundred milliseconds after onset of depolarization and once started followed an exponential time course with a time constant of several seconds or longer. By contrast, in whole-cell recordings from muscle cells (Giannattasio et al., 1991; Hadley and Lederer, 1991), mammalian pituitary tumor cells $\left(\mathrm{GH}_{3}\right)$ (Kalman et al., 1988), hippocampal neurons (Köhr and Mody, 1991; Köhr et al., 1991) and in single-channel recordings from cardiac myocytes (Yue et al., 1990), calcium-dependent inactivation of L-type channels proceeds with a time scale of tens of milliseconds, and there is no delay in the onset of inactivation after depolarization. Thus, inactivation of L-type calcium channels in the bipolar-cell synaptic terminal is at least 100 -fold slower than in other cells. Recovery from inactivation was also much slower in bipolar neurons, with a time constant of $\sim 25$ vs $\sim 0.2 \mathrm{sec}$ in smooth-muscle cells (Giannattasio et al., 1991). This suggests that the underlying mechanisms may be fundamentally different for the slow and the fast inactivation processes, even though both are apparently triggered by elevated $\left[\mathrm{Ca}^{2+}\right]_{\mathrm{i}}$.

For fast calcium-dependent inactivation, evidence suggests that inactivation occurs because of direct binding of $\mathrm{Ca}^{2+}$ to the calcium channel molecule itself (Haack and Rosenberg, 1994; Imredy and Yue, 1994; Neely et al., 1994) or to a $\mathrm{Ca}^{2+}$-sensitive regulatory enzyme closely associated with the channel (Armstrong and Eckert, 1987; Armstrong et al., 1991; Hadley and Lederer, 1991). One indication that fast inactivation involves $\mathrm{Ca}^{2+}$-binding at or near the channel is that BAPTA has little effect on inactivation in patches containing only one calcium channel (Imredy and Yue, 1992) and in L-type channels expressed in Xenopus oocytes (Neely et al., 1994). In contrast, inactivation of calcium current in bipolar neurons was greatly reduced in the presence of intracellular BAPTA. Because calcium buffers are effective at reducing $\left[\mathrm{Ca}^{2+}\right]_{\mathrm{i}}$ only at distances greater than a few tens of nanometers from the calcium-channel pore (Stern, 1992), this implies that the distance of the relevant calcium sensor from the channel is greater for the slow inactivation observed in our experiments than for the fast inactivation described for L-type channels in muscle cells. Calcium channel gating is also known to be altered by channel phosphorylation (Chad and Eckert, 1986; Armstrong and Eckert, 1987; Armstrong et al., 1991) and by interactions with the cytoskeleton (Johnson and Byerly, 1993). Although such indirect mechanisms might act rapidly provided the relationship between the channel protein and the ancillary proteins is molec- 
ularly close, the slow and delayed inactivation we have observed is suggestive of an indirect mechanism of calcium-dependent inactivation, such as channel phosphorylation/dephosphorylation.

Dialysis of bipolar-cell synaptic terminals with elevated $\left[\mathrm{Ca}^{2+}\right]$ showed that $1.4 \mu \mathrm{M}\left[\mathrm{Ca}^{2+}\right]_{\mathrm{i}}$ was insufficient to produce inactivation of calcium current. This level of $\left[\mathrm{Ca}^{2+}\right]_{i}$ exceeds the spatially averaged increase in $\left[\mathrm{Ca}^{2+}\right]_{i}$ measured by Fura-2 in terminals during activation of calcium current and is in the range expected for the "shell" of high calcium under the membrane when calcium influx is driven via plasma-membrane calcium channels. The relevant level of $\left[\mathrm{Ca}^{2+}\right]_{i}$ that triggers inactivation in the bipolar-cell synaptic terminal thus is not the level achieved at long distance (micrometers) from clusters of calcium channels. However, calcium current inactivated when terminals were dialyzed with solutions containing $20-50 \mu \mathrm{M}\left[\mathrm{Ca}^{2+}\right]$, indicating that the calcium sensor for inactivation has relatively low affinity. Domain models of calcium diffusion from a single open calcium channel (Chad and Eckert, 1984) suggest that concentrations of free $\mathrm{Ca}^{2+}$ greater than $\sim 10 \mu \mathrm{M}$ could be attained at a distance of $20-50 \mathrm{~nm}$ from the pore, depending on buffering conditions (Stern, 1992). This very limited spatial domain of high $\left[\mathrm{Ca}^{2+}\right]_{i}$ has been termed the nanodomain (Schweizer et al., 1995). Alternatively, the same level of $\left[\mathrm{Ca}^{2+}\right]_{i}$ could be attained at longer average distance between the calcium sensor and calcium-channel pores if the sensor is located within the overlapping domains of several open calcium channels (Fogelson and Zucker, 1985; Sherman et al., 1990). The latter arrangement, called the microdomain by Schweizer et al. (1995), would seem to satisfy the conditions for both dependence on high $\left[\mathrm{Ca}^{2+}\right]_{i}$ and a pronounced effect of exogenous BAPTA. If the calcium sensor for inactivation is indeed located within the overlapping domains of a cluster of calcium channels, then $\left[\mathrm{Ca}^{2+}\right]_{\mathrm{i}}$ would be expected to increase rapidly upon channel activation. Thus, the observed long delay and slow rate of inactivation presumably reflects the kinetics of the inactivation machinery downstream from the binding of $\mathrm{Ca}^{2+}$, rather than the speed of the change in $\left[\mathrm{Ca}^{2+}\right]_{i}$ itself.

The absence of rapid inactivation of calcium current also has been observed in the squid giant synapse, in which calcium current shows no inactivation during depolarizations lasting $40 \mathrm{msec}$ (Llinás et al., 1981). In addition, the calcium action potential of the squid presynaptic terminal shows a prolonged plateau, suggesting slow inactivation of calcium current (Katz and Miledi, 1971). Consistent with this, Augustine and Eckert (1984) report a time constant of $1.5 \mathrm{sec}$ for calcium-dependent inactivation of the calcium current in squid presynaptic terminals, whereas recovery from inactivation was even slower, with a time constant of $\sim 70$ sec. Similarly, in the presynaptic terminals of the chick ciliary ganglion, calcium current does not inactivate rapidly (Stanley and Goping, 1991), and inactivation is enhanced by higher levels of external calcium (Yawo and Momiyama, 1993). Thus, in preparations in which direct measurement of presynaptic calcium current is feasible, slow inactivation seems to be the rule.

Calcium-dependent inactivation of presynaptic calcium channels represents a negative feedback influencing the release of neurotransmitter during sustained depolarization of bipolar neurons. The large-terminal goldfish bipolar neurons used in our experiments represent a class of rod-dominant, ON-type bipolar cell (Saito et al., 1983) that depolarizes during illumination. Inactivation of calcium current thus joins other negative feedback mechanisms that have been described previously, including activation of chloride conductance and inhibition of calcium current produced by GABAergic feedback from amacrine cells (Matthews et al., 1994), activation of calcium-dependent potassium conductance (Kaneko and Tachibana, 1985), and calcium-dependent inhibition of vesicle recycling (von Gersdorff and Matthews, 1994b). Because of its slow onset, inactivation of calcium current would be expected to contribute to the slowing of sustained transmitter release only for depolarizations lasting longer than $\sim 500$ msec. Under conditions of dim illumination, the dominant form of feedback inhibition likely would be the GABA-activated chloride conductance, which tends to clamp the membrane potential of the bipolar neuron below the activation range of the calcium current (Heidelberger and Matthews, 1991). When illumination conditions change to higher sustained levels, however, calcium-dependent inactivation of the presynaptic calcium current in bipolar cells may help to reduce the synaptic gain in the highsensitivity, rod-dominated pathway in the retina.

\section{REFERENCES}

Armstrung D, Eckert R (1987) Voltage-activaled calcium channels that must be phosphorylated to respond to membrane depolarization. Proc Natl Acad Sci USA 84:2518-2522.

Armstrong DL, Rossier MF, Shcherbatko AD, White RE (1991) Enzymatic gating of voltage-activated calcium channels. Ann NY Acad Sci 635:26-34.

Augustine GJ, Eckert R (1984) Calcium-dependent inactivation of presynaptic calcium channels. Soc Neurosci Abstr 10:194.

Bechem M, Pott L (1985) Removal of Ca current inactivation in dialysed guinea-pig atrial cardioballs by $\mathrm{Ca}$ chelators. Pflügers Arch 404:10-20.

Brehm P, Eckert R (1978) Calcium entry leads to inactivation of calcium channel in Paramecium. Science 202:1203-1206.

Chad JE, Eckert R (1984) Calcium domains associated with individual channels can account for anomalous voltage relations of Ca-dependent responses. Biophys J 45:993-999.

Chad JE, Eckert R (1986) An enzymatic mechanism for calcium current inactivation in dialysed Helix neurones. J Physiol (Lond) 378:31-51.

Fogelson AL, Zucker RS (1985) Presynaptic calcium diffusion from various arrays of single channels. Implications for transmitter release and synaptic facilitation. Biophys J 48:1003-1017.

Giannattasio B, Jones SW, Scarpa A (1991) Calcium currents in the A7r5 smooth muscle-derived cell line. Calcium-dependent and voltage-dependent inactivation. J Gen Physiol 98:987-1003.

Haack JA, Rosenberg RL (1994) Calcium-dependent inactivation of Ltype calcium channels in planar lipid bilayers. Biophys $\mathrm{J}$ 66:1051-1060.

I Iadlcy RW, Lederer WJ (1991) $\mathrm{Ca}^{2+}$ and voltage inactivatc $\mathrm{Ca}^{2+}$ channels in guinea-pig ventricular myocytes through independent mechanisms. J Physiol (Lond) 444:257-268.

Heidelberger R, Matthews $G$ (1991) Inhibition of calcium influx and calcium current by $\gamma$-aminobutyric acid in single synaptic terminals. Proc Natl Acad Sci USA 88:7135-7139.

Heidelberger R, Matthews G (1992) Calcium influx and calcium current in single synaptic terminals of goldfish retinal bipolar neurons. J Physiol (Lond) 447:235-256.

Heidelberger R, Matthews $G$ (1994) Dopamine enhances $\mathrm{Ca}^{2+}$ responses in synaptic terminals of retinal bipolar neurons. NeuroReport 5:729-732.

Imredy JP, Yue DT (1992) Submicroscopic $\mathrm{Ca}^{2+}$ diffusion mediates inhibitory coupling between individual $\mathrm{Ca}^{2+}$ channels. Neuron 9:197-207.

Imredy JP, Yue DT (1994) Mechanism of $\mathrm{Ca}^{2+}$-sensitive inactivation of L-type $\mathrm{Ca}^{2+}$ channels. Neuron 12:1301-1318.

Ishida AT, Stell WK, Lightfoot DA (1980) Rod and cone inputs to bipolar cells in goldfish retina. J Comp Neurol 191:315-335.

Johnson BD, Byerly L (1993) A cytoskeletal mechanism for $\mathrm{Ca}^{2+}$ channel metabolic dependence and inactivation by intracellular $\mathrm{Ca}^{2+}$. Neuron 10:797-804.

Kalman D, O'Lague PH, Erxleben C, Armstrong DL (1988) Calciumdependent inactivation of the dihydropyridine-sensitive calcium channels in $\mathrm{GH}_{3}$ cells. J Gen Physiol 92:531-548.

Kaneko A, Tachibana M (1985) A voltage-clamp analysis of membrane currents in solitary bipolar cells dissociated from Carassius auratus. J Physiol (Lond) 385:131-152.

Katz B, Miledi R (1971) The effect of prolonged depolarization on synaptic transfer in the stellate ganglion of the squid. J Physiol (Lond) $216: 503-512$ 
Köhr G, Mody I (1991) Endogenous intracellular calcium buffering and the activation/inactivation of HVA calcium currents in rat dentate gyrus granule cells. J Gen Physiol 98:941-967.

Köhr G, Lambert CE, Mody I (1991) Calbindin-D ${ }_{28 \mathrm{~K}}(\mathrm{CaBP})$ levels and calcium currents in acutely dissociated epileptic neurons. Exp Brain Res 85:543-551.

Konishi M, Hollingworth S, Harkins AB, Baylor SM (1991) Myoplasmic calcium transients in intact frog skeletal muscle fibers monitored with the fluorescent indicator furaptra. J Gen Physiol 97:271-301.

Kostyuk PG, Krishtal OA (1977) Effects of calcium and calcium-chelating agents on the inward and outward current in the membrane of mollusk neurones. J Physiol (Lond) 270:569-580.

Lemos JR, Nowycky MC (1989) Two types of calcium channels coexist in peptide-releasing vertebrate nerve terminals. Neuron 2:1419-1426.

Llinás R, Steinberg IZ, Walton K (1981) Relationship between presynaptic calcium current and postsynaptic potential in squid giant synapse. Biophys J 33:323-352.

Matthews G, Ayoub GS, Heidelberger R (1994) Presynaptic inhibition by GABA is medialed via two distinct GABA receptors with novel pharmacology. J Neurosci 14:1079-1090.

Neely A, Olcese R, Wei X, Birnbaumer L, Stefani E (1994) $\mathrm{Ca}^{2+}$-dependent inactivation of a cloned cardiac $\mathrm{Ca}^{2+}$ channel $\alpha 1$ subunit $(\alpha 1 \mathrm{C})$ expressed in Xenopus oocytes. Biophys J 66:1895-1903.

Neher E (1988) The influence of intracellular calcium concentration on degranulation of dialysed mast cells from rat peritoneum. J Physiol (Lond) 395:193-214.

Saito T, Kondo H, Toyoda J (1979) Ionic mechanisms of two types of ON-center bipolar cells in the carp retina. J Gen Physiol 73:73-90.

Saito T, Kujiraoka T, Yonaha T (1983) Connections between photoreceptors and horseradish peroxidase-injectcd bipolar cclls in the carp retina. Vision Res 23:353-362.
Schweizer FE, Betz H, Augustine GJ (1995) From vesicle docking to endocytosis: intermediate reactions of exocytosis. Neuron 14:689-696.

Sherman A, Keizer J, Rinzel J (1990) Domain model for $\mathrm{Ca}^{2+}$-inactivation of $\mathrm{Ca}^{2+}$ channels at low channel density. Biophys J 58:985-995.

Stanley EF, Goping G (1991) Characterization of a calcium current in a vertebrate cholinergic presynaptic nerve terminal. J Neurosci 11:985-993.

Stern MD (1992) Buffering of calcium in the vicinity of a channel pore. Cell Calcium 13:183-192.

Tachibana M (1983) Ionic current of solitary horizontal cells isolated from goldfish retina. J Physiol (Lond) 345:329-351.

Tachibana M, Okada T, Arimura T, Kobayashi K, Piccolino M (1993) Dihydropyridine-sensitive calcium current mediates neurotransmitter release from bipolar cells of the goldfish retina. J Neurosci 13:2898-2909.

Tillotson D (1979) Inactivation of Ca conductance dependent on en try of $\mathrm{Ca}$ ions in molluscan neurons. Proc Natl Acad Sci USA $76: 1497-1500$

von Gersdorff H, Matthews G (1994a) Dynamics of synaptic vesicle fusion and membrane retrieval in synaptic terminals. Nature 367:735-739.

von Gersdorff II, Matthews G (1994b) Inhibition of endocytosis by elevated internal calcium in a synaptic terminal. Nature 370:652-655.

Yawo H, Momiyama A (1993) Re-evaluation of calcium currents in preand post-synaptic neurons of the chick ciliary ganglion. J Physiol (Lond) 460:153-172

Yazulla S, Studholme KM, Wu J-Y (1987) GABAergic input to the synaptic terminals of $\mathrm{Mb}-1$ bipolar cells in the goldfish retina. Brain Res 411:400-405.

Yue DT, Backx PH, Imredy JP (1990) Calcium-sensitive inactivation in the gating of single calcium channels. Science 250:1735-1738. 